DOI: 10.26730/1999-4125-2020-3-33-44

УДК 622.411.5: 622.33

ВОПРОСЫ КОНТРОЛЯ КОНЦЕНТРАЦИЙ УГЛЕРОДСОДЕРЖАЩЕЙ ПЫЛИ В АТМОСФЕРНОМ ВОЗДУХЕ ПРИ ДОБЫЧЕ И ПЕРЕРАБОТКЕ УГЛЯ

\title{
CARBON-CONTAINING DUST CONCENTRATIONS CONTROL IN THE ATMOSPHERIC AIR DURING COAL MINING AND PROCESSING
}

\author{
Журавлева Наталья Викторовна ${ }^{1,2}$, \\ доктор техн. наук, доцент, \\ генеральный директор, e-mail: natalia_zhuravleva62@mail.ru \\ Natalia V. Zhuravleva ${ }^{1,2}$, \\ D. Sc. in Engineering, Associate Professor,
} General Director, e-mail: natalia_zhuravleva62@mail.ru

Хабибулина Екатерина Рафисовна ${ }^{1}$, канд. хим. наук, руководитель отдела, e-mail: khabibulina_er@mail.ru Ekaterina R. Khabibulina, C. Sc. in Chemistry, Head of Department Журавлева Екатерина Владимировна ${ }^{3}$, аспирант, e-mail: katezhurav@yandex.ru Ekaterina V. Zhuravleva ${ }^{3}$, Postgraduate Михайлова Екатерина Сергеевна ${ }^{3,4}$, канд. хим. наук, e-mail: e_s_mihaylova@mail.ru Ekaterina S. Mikhaylova ${ }^{3,4}$, C. Sc. in Chemistry

Исмагилов Зинфер Ришатович ${ }^{3,4}$, академик РАН, профессор, научный руководитель ФИЦ УУХ С ОРАН, заведующий кафедрой, e-mail: zinfer1 @ mail.ru Zinfer R. Ismagilov ${ }^{3,4}$, RAS Academician, Professor, Academic Advisor, FRC CCC SB RAS, Head of Department

${ }^{1} \mathrm{AO}$ «Западно-Сибирский испытательный центр», Россия, 654005, г. Новокузнецк, ул.

Орджоникидзе, 9

${ }^{1}$ JSC West-Siberian Mining Test Center, Russia, 654005, Novokuznetsk, Ordzhonikidze street, 9

${ }^{2}$ Сибирский государственный индустриальный университет, Россия, 654006, г. Новокузнецк, ул. Кирова, 42

${ }^{2}$ Siberian State Industrial University, Russia, 654006, Novokuznetsk, Kirova street, 42

${ }^{3}$ «Федеральное государственное бюджетное научное учреждение «Федеральный исследовательский центр угля и углехимии Сибирского отделения Российской академии наук» (ФИЦ УУХ СО РАН); Россия, 650000, г. Кемерово, пр-т Советский, 18

${ }^{3}$ Federal State Budget Scientific Centre «The Federal Research Center of Coal and Coal-Chemistry of Siberian Branch of the Russian Academy of Sciences»; Russia, 650000, Kemerovo, Soviet Avenue, 18 ${ }^{4}$ Кузбасский государственный технический университет имени Т.Ф. Горбачева, 650000, Россия, г. Кемерово, ул. Весенняя, 28

${ }^{4}$ T.F. Gorbachev Kuzbass State Technical University, Russia, 650000, Kemerovo, 28 street

Vesennyaya

Аннотация:

В данной работе представлен обзор отечественных и зарубежных методов и подходов к контролю углеродсодержащей пыли в атмосферном воздухе в зоне действия предприятий по добыче и переработке углей. Основной состав взвешенных веществ (угольной пыли), поступаюших в атмосферу в проиессах добычи и переработки угля, состоит из неорганической части, представленной основными 
породообразующими оксидами, токсичными элементами, минеральными частицами РМ2,5 и РМ10, а также органических веществ, в состав которых входят сажа (углерод), органическое вещество угля, бенз(а)пирен и другие ПАУ. Содержание токсичных элементов в углях может существенно отличаться в пределах даже отдельного угольного месторождения, поэтому изучение элементного состава углей Кузнецкого угольного бассейна и продуктов их переработки необходимо проводить с иелью разработки новых геотехнологий комплексного освоения угольных месторождений и планирования мониторинга объектов окружающей среды в зоне действия предприятий по добыче и переработке углей. Для оценки токсичности тонкодисперсных угольных систем необходимо выполнять измерение распределения частии по размерам с определением доли наиболее опасных классов. Для этих иелей наиболее информативным и достоверным является метод лазерной дифракции. Данные о составе и свойствах угольной пьли предприятий Кузбасса получены на основе исследований углей, вскрышных и вмещающих пород и содержат результаты определения токсичных элементов, ПАУ, гранулометрического состава. Разработка научных основ и практических методов извлечения полиароматических углеводородов из каменных углей Кузбасса и изучение распределения представителей данного класса канцерогенных соединений в регионе является актуальным направлением, необходимым для прогнозирования канцерогенной опасности при добыче, транспортировке и переработке угля.

Ключевые слова: добыча и переработка углей, пыль каменного угля, взвешенные частищы РМ10 и PM2,5 в атмосферном воздухе, полициклические ароматические углеводороды, токсичные элементы.

\begin{abstract}
:
An overview of Russian and foreign methods and approaches to control carbon-containing dust in the atmospheric air in the operation area of coal mining and processing enterprises is presented in this paper. The main composition of suspended substances (coal dust) emitted in the atmosphere in the processes of coal mining and processing includes an inorganic part, represented by the main rock-forming oxides, toxic elements, mineral particles PM2,5 and PM10, also organic substances, which include soot (carbon), organic matter of coal, benz(a)pyrene and other PAHs. The toxic elements content in coal can vary significantly within even a single coal basin; so the study of the elemental coal composition in the Kuznetsk coal basin and their processing products must be carried out in order to develop new geotechnologies for integrated development of coal deposits and planning monitoring of environmental objects in the operation area of coal mining and processing enterprises. It is necessary to measure the particle size distribution and determine the proportion of the most dangerous classes for estimating the toxicity of fine coal systems. The laser diffraction method is the most informative and reliable method for these purposes. The data of the composition and properties of coal dust of Kuzbass enterprises were obtained on the basis of studies of coal, overburden and host rock and contain the results of toxic elements, PAHs, and granulometric composition determination. The development of scientific bases and practical methods for polyaromatic hydrocarbons extraction from Kuzbass coal and the study of the distribution of these carcinogenic compounds representatives in the region is actual and necessary for predicting the carcinogenic hazard in coal mining, transportation and processing.
\end{abstract}

Key words: coal mining and processing, coal dust, suspended particles PM10 and PM2,5 in the atmospheric air, polycyclic aromatic hydrocarbons, toxic elements.

\section{Введение}

Наибольшую нагрузку на окружающую среду Кузбасса оказывают угледобывающие и углеперерабатывающие предприятия региона. Одной из основных экологических проблем области является загрязнение атмосферного воздуха. На сегодняшний день работы по оценке экологической нагрузки на атмосферный воздух предприятияи угледобывающей и углеперерабатывающей промышленности проводятся по традиционным схемам, которые не изменялись десятки лет и во многом не удовлетворяют современным требованиям. Практически отсутствуют методические подходы по анализу многокомпонентных природных систем для дифференцированного количественного определения отдельных показателей загрязнения. Возможности современных физико-химических методов анализа, существенно повышающих точность, надежность и информативность контроля состояния атмосферного воздуха, сегодня еще слабо используются в производственном экологическом контроле.

В данной работе представлен обзор отечественных и зарубежных методов по контролю концентраций углеродсодержащей пыли в атмосферном воздухе в зоне действия предприятий по добыче и переработке углей, применение которых актуально в соответствии с современными изменениями в природоохранном законодательстве. Данные о составе и свойствах угольной пыли, полученные на основе исследований углей Кузбасса, отходов их добычи и переработки, должны быть использованы при составлении программ производственного экологического мониторинга предприятиями 
отрасли.

В зарубежных исследованиях, направленных на изучение экологических проблем угольной отрасли [1], авторы рассматривают угольную пыль как источник определенного ряда токсичных соединений для человека и окружающей среды. К этому ряду относятся:

- тонкодисперсный материал, который характеризуется определенным содержанием диоксида кремния (до $5 \%$ или более этой величины) и распределением частиц мелких классов по размерам (от 1 до 10 мкм);

- токсичные металлы, которые являются загрязнителями атмосферного воздуха (ртуть, свинец и др.), а также способствующие образованию активных форм кислорода в организме человека (железо, медь др.);

полициклические ароматические углеводороды (ПАУ) из списка 16 приоритетных соединений, включая бенз(а)пирен, бенз(а)антрацен, хризен;

- трициклические ПАУ, включая фенантрен и его алкилзамещенные производные.

Таким образом, основной состав взвешенных веществ (угольной пыли), поступающих в атмосферу в процессах добычи и переработки угля, состоит из неорганической части, представленной основными породообразующими оксидами, токсичными элементами, минеральными частицами класса менее 2,5 мкм (РМ2,5) и класса менее 10 мкм (РМ10), а также органических веществ, в состав которых входят сажа (углерод), органическое вещество угля, бенз(а)пирен и другие ПАУ.

В настоящее время в области изучения состава и свойств пыли, образующейся при добыче, переработке и транспортировке углей, имеются следующие проблемы:

- основной массив аналитических данных по элементному составу углей и продуктов их добычи и переработки был получен в основном полуколичественными спектральными методами анализа и требует уточнения;

- содержание токсичных индивидуальных полициклических ароматических углеводородов в углях, продуктах их добычи и переработки не определяется;

- определение частиц мелких классов (РМ2,5 и РМ10) в угольной пыли при экологическом мониторинге атмосферного воздуха и промышленных выбросов не осуществляется.

Надежное методическое обеспечение в части оценки тонкодисперсных углеродсодержащих материалов (угольной пыли, шламов, выбросов в атмосферу углеобогатительных фабрик и др.), а также в части определения органических загрязнителей (компонентов взрывчатых веществ, реагентов, применяемых при пылеподавлении, при борьбе со смерзаемостью при складировании и транспортировке углей) отсутствует, поэтому разработка соответствующих методик определения является актуальной и востребованной.

\section{Углефильные элементы в углях и пыли} каменного угля

На основании анализа литературных данных о содержании токсичных элементов в углях может быть предложен их приоритетный ряд для определения в объектах окружающей среды в зоне действия предприятий по добыче и переработке углей. Перечень должен содержать токсичные элементы и потенциально токсичные элементы углей (As, Be, Cl, Co, Cr, F, Hg, Mn, Ni, V, Pb, Sr, $\mathrm{Sb}, \mathrm{Se}, \mathrm{Tl}, \mathrm{V}, \mathrm{Zn}, \mathrm{U}, \mathrm{Th}, \mathrm{Ra}, \mathrm{Rn}$ ) [2]. Этот ряд может быть дополнен элементами, являющимися высокоуглефильными (Ag, Sb, Tl, As, Mo, I, Ge, Hg, $\mathrm{Bi}, \mathrm{Se}$ ), углефильными (Ni, Hf, Sn, La, Co, Ba, Sc, $\mathrm{Nb}, \mathrm{Sr}, \mathrm{Th}, \mathrm{Ga}, \mathrm{Cu}, \mathrm{Zn}, \mathrm{W}, \mathrm{Au}, \mathrm{In}, \mathrm{Pb}, \mathrm{U}, \mathrm{B}, \mathrm{Be})$, слабо- или умеренно углефильными (Ti, Zr, F, Cd, V, Ta, Cr, Y, Li, P) [3].

При осуществлении экологического мониторинга в зоне влияния предприятий по добыче и переработке углей необходимо также учитывать перечень загрязняющих веществ, в отношении которых применяются меры государственного регулирования в области охраны окружающей среды [4]. Данный нормативный документ содержит перечни токсичных элементов для их определения в атмосферном воздухе $(\mathrm{V}, \mathrm{Cd}$, $\mathrm{Co}, \mathrm{Mn}, \mathrm{Cu}, \mathrm{As}, \mathrm{Ni}, \mathrm{Hg}, \mathrm{Pb}, \mathrm{Cr}, \mathrm{F}, \mathrm{Cl}$ ), водных объектах (Be, B, Bi, V, W, Cd, Co, Li, Mn, Cu, As, $\mathrm{Ni}, \mathrm{Hg}, \mathrm{Pb}, \mathrm{Sb}, \mathrm{Se}, \mathrm{Sr}, \mathrm{Cr}, \mathrm{F}, \mathrm{Zn}$ ), почвах (V, Cd, Co, $\mathrm{Mn}, \mathrm{Cu}, \mathrm{As}, \mathrm{Ni}, \mathrm{Hg}, \mathrm{Pb}, \mathrm{Sb}, \mathrm{Cr}, \mathrm{F}, \mathrm{Zn}$ ) [4].

Содержание токсичных элементов в углях может существенно отличаться в пределах даже отдельного угольного месторождения, поэтому изучение элементного состава углей Кузнецкого угольного бассейна и продуктов их переработки необходимо проводить с целью разработки новых геотехнологий комплексного освоения угольных месторождений и планирования мониторинга объектов окружающей среды в зоне действия предприятий по добыче и переработке углей.

Например, одним из значимых углефильных элементов, загрязняющих окружающую среду в Кемеровской области, является мышьяк. В табл. 1 представлены данные о концентрациях данного элемента, которые обнаруживаются в почвах в зоне влияния угледобывающих предприятий Кузбасса.

В соответствии с гигиеническими нормативами ГН 2.1.7.2511-09 [5] установлены следующие нормативы ПДК мышьяка для различных типов почв: песчаные и супесчаные - 2 мг/кг; кислые (суглинистые и глинистые), $\mathrm{pH} \mathrm{KCl}$ $<5,5-5$ мг/кг; близкие к нейтральным, нейтральные (суглинистые и глинистые), $\mathrm{pH} \mathrm{KCl>}$ $5,5-10$ мг/кг. Таким образом, контроль содержаний данного элемента как в углях месторождений, так и в пыли каменного угля 
является необходимым.

Распределение основных породообразующих элементов и микроэлементов в углях Кузбасса, отходах их добычи и переработки рассмотрено ранее в работах [6-8].

Необходимо отметить, что такие элементы, как железо и марганец, типичны для углей и вскрышных и вмещающих пород угольных месторождений Кузбасса. Определение этих элементов, поступающих в составе угольной пыли в объекты окружающей среды как составной части пыли каменного угля, также должно входить в программы мониторинга атмосферного воздуха.

\section{Полициклические углеводороды в углях \\ Полициклические \\ ароматические \\ ароматические} углеводороды (ПАУ) входят в состав органической массы углей и относятся к стойким экотоксикантам. Содержание индивидуальных ПАУ в углях зависит от природы исходного растительного материала, участвовавшего в этапах углеобразования, а также термодинамических условий протекания данного процесса [9]. Изучение содержания ПАУ в углях актуально по ряду причин, в том числе для уточнения структуры органической части угля, частично состоящей из фрагментов молекул ПАУ, а также для определения степени токсичности сырья, продукции и атмосферного воздуха угледобывающих и углеперерабатывающих предприятий. В работах [10-15] рассмотрены аналитические методы определения ПАУ в углях и особенности распределения представителей данного класса соединений.

При изучении распределения ПАУ в почвах Кузбасса на границах санитарно-защитных зон предприятий по добыче угля открытым и закрытым способом показано, что содержание фенантрена находится в диапазоне от 0,0012 до 0,0031 мг/кг, при этом бенз(а)пирен в почвах не обнаруживается. Другое распределение ПАУ в почвах наблюдается в зоне влияния предприятий по обогащению угля: содержание фенантрена находится в диапазоне от 0,0015 до 0,0432 мг/кг, концентрация бенз(а)пирена - от <0,001 до 0,0390 мг/кг (2 ПДК) [16]. Таким образом, предприятия по обогащению угля являются источниками поступления ПАУ в окружающую среду, в том числе канцерогенного бенз(а)пирена.

На сегодняшний день в РФ существуют методики, допущенные для целей экологического контроля, которые позволяют определять все 16 приоритетных ПАУ в атмосферном воздухе, промышленных выбросах, водных объектах, почвах, однако в данных объектах установлены величины ПДК только для бенз(а)пирена и нафталина. Таким образом, несовершенство нормативной базы приводит к необъективным оценкам уровня содержания канцерогенных соединений в объектах окружающей среды. Особенно актуальна эта информация для предприятий по добыче и переработке углей, учитывая тот факт, что угли разных марок могут содержать значительные концентрации ПАУ [17, $18]$.

В настоящее время в отечественных и зарубежных источниках большое внимание уделяется изучению как углей, являющихся источником поступления ПАУ в окружающую среду [19], так и самих объектов окружающей среды, загрязненных ПАУ (атмосферного воздуха [20-24], воды природного происхождения [16, 2528], почв [29-31], растительного покрова [32, 33]).

Исследования по изучению распределения ПАУ в углях и продуктах их переработки будут проводиться при финансовой поддержке РФФИ и Департамента образования и науки Кемеровской области в рамках научного проекта № 20-45420020/20 «Разработка научных основ и практических методов извлечения полиароматических углеводородов из каменных углей Кузбасса и изучение распределения представителей данного класса канцерогенных соединений в регионе для прогнозирования онкологической опасности при добыче, транспортировке и переработке угля» в период 2020-2022 гг. Разработка научных основ и практических методов извлечения полиароматических углеводородов из каменных углей Кузбасса и изучение распределения представителей данного класса канцерогенных соединений в регионе является актуальным направлением, необходимым для прогнозирования канцерогенной опасности при добыче, транспортировке и переработке угля, в том числе для оценки возможной степени глобальной экологической опасности для региона.

\section{Тонкодисперсные частицы пыли} каменного угля мелких классов (в том числе рм2,5 и рм10)

На здоровье человека оказывают влияние частицы с диаметром менее 10 мкм (РМ10) и частицы диаметром менее 2,5 мкм (РM2,5). Частицы РM2,5 - это мелкодисперсные взвешенные частицы, в данную категорию также входят ультра-мелкодисперсные частицы диаметром менее 0,1 мкм. Основная проблема с мелкодисперсными частицами заключается в том, что частицы диаметром от 0,1 мкм до 1 мкм могут находиться в атмосферном воздухе в течение многих дней и недель, и вследствие этого частицы переносятся по воздуху на большие расстояния. Всемирная организация здравоохранения (ВО3) считает частицы пыли в воздухе одной из серьезнейших опасностей и причин множества заболеваний дыхательных путей и сердечнососудистой системы. Предельные концентрации частиц РМ10 и РМ2,5 в воздухе установлены в 
Таблица 1. Валовое содержание мышьяка в почвах в зоне влияния угледобывающих предприятий Кузбасса

Table 1. Arsenic total content in soils in the zone of influence of Kuzbass coal mining enterprises

\begin{tabular}{|c|c|c|}
\hline $\begin{array}{c}\text { Наименование угольного } \\
\text { месторождения }\end{array}$ & $\begin{array}{c}\text { Минимальное валовое } \\
\text { содержание мышьяка, мг/кг }\end{array}$ & $\begin{array}{c}\text { Максимальное валовое } \\
\text { содержание мышьяка, мг/кг }\end{array}$ \\
\hline Уропское & 14,7 & 350,6 \\
\hline Бунгурское & 11,9 & 26,6 \\
\hline Талдинское & 12,2 & 673,4 \\
\hline Жерновское & 13,2 & 23,7 \\
\hline Новоказанское & 23,3 & 581,0 \\
\hline
\end{tabular}

Таблица 2. Рекомендации ВО3 по целевым уровням концентраций твердых частиц РМ10 и РМ2,5 и нормативы, принятые в РФ

Table 2. WHO recommendations on target levels of PM10 and PM2,5 solid particle concentrations and standards adopted in the Russian Federation

\begin{tabular}{|c|c|c|c|c|c|}
\hline \multirow[t]{2}{*}{ Показатель } & \multirow{2}{*}{$\begin{array}{c}\text { Максимальная } \\
\text { разовая } \\
\text { концентрация, } \\
\text { мг/м } \\
\text { РФ }\end{array}$} & \multicolumn{2}{|c|}{ 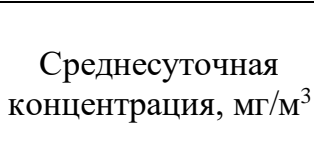 } & \multicolumn{2}{|c|}{$\begin{array}{c}\text { Среднегодовая } \\
\text { концентрация, } \\
\text { мг/м }\end{array}$} \\
\hline & & $\mathrm{BO} 3$ & $\mathrm{P} \Phi$ & $\mathrm{BO} 3$ & РФ \\
\hline Твердые частицы РМ2,5 & 0,16 & 0,025 & 0,035 & 0,010 & 0,025 \\
\hline Твердые частицы PM10 & 0,30 & 0,050 & 0,060 & 0,020 & 0,040 \\
\hline
\end{tabular}

документе под названием «Руководство по качеству воздуха» в виде среднесуточных и среднегодовых величин [34], в РФ их содержание нормировано в документе [35]. По мнению экспертов ВО3, только достижение таких уровней концентраций пыли в воздухе может позволить снизить смертность от легочных и сердечных заболеваний, связанных с загрязнением атмосферного воздуха. Российские нормативы, принятые в 2010 году, менее требовательны к качеству атмосферного воздуха и воздуха в помещениях. Однако надо понимать, что приведенные рекомендации ВОЗ - это всего лишь «идеал, к которому следует стремиться».

Определение взвешенных частиц РМ10 и PM2,5 в атмосферном воздухе должно быть обязательным для предприятий по добыче и переработке угля. Содержание этих частиц в атмосферном воздухе нормировано, разработаны методики определения, доступны средства измерения. Однако на территории Кемеровской области определение данных показателей в атмосферном воздухе населенных мест и на границах санитарно-защитных зон промышленных предприятий не проводится, хотя взвешенные частицы РМ10 и РМ2,5 также включены в РФ в перечень загрязняющих веществ, в отношении которых применяются меры государственного регулирования в области охраны окружающей среды [4].

Для оценки токсичности тонкодисперсных угольных систем необходимо выполнять измерение распределения частиц по размерам с определением доли наиболее опасных классов. Для этих целей наиболее информативным и достоверным является метод лазерной дифракции [36].

\section{Перечень методик, разрешенных в рф для определения пыли, в том числе углеродсодержащей, в атмосферном воздухе, воздухе рабочей зоны, выбросах в атмосферу}

Для определения общей концентрации пыли, пыли каменного угля, сажи в воздушных средах применяются нормативные документы (см. табл. 3), в которых используются гравиметрические и фотометрические методы анализа. Поскольку пыль, образующаяся при процессах добычи и переработки угля, представляет собой сложную смесь неорганических соединений (основные породообразующие оксиды и микроэлементы), органического вещества угля, сажи, то селективность аналитических методов анализа относительно этих компонентов должна быть существенной. Однако гравиметрический метод определения угольной пыли (именно углеродной ее части) по нормативному документу [42] имеет ряд практических недостатков. Так, после кислотного растворения неорганической части пыли проводится длительная отмывка фильтра до нейтральной реакции промывных вод, что может приводить к потере углеродной части пробы. Измерения массовой концентрации углеродсодержащего аэрозоля (сажи) по нормативному документу [43] выполняют методом, который основан на улавливании частиц углеродсодержащего аэрозоля (сажи) из воздуха на перхлорвиниловый фильтр АФА-ХП-10 (или АФА-ВП-10), последующем растворении фильтра в ДМСО и определении содержания сажи в пробе 
Таблица 3. Перечень методик, разрешенных в РФ для определения пыли, в том числе углеродсодержащей, в атмосферном воздухе, воздухе рабочей зоны, выбросах в атмосферу

Table 3. List of methods allowed in the Russian Federation for determining dust, including carbon-containing dust, in atmospheric air, work zone air, and atmospheric emissions

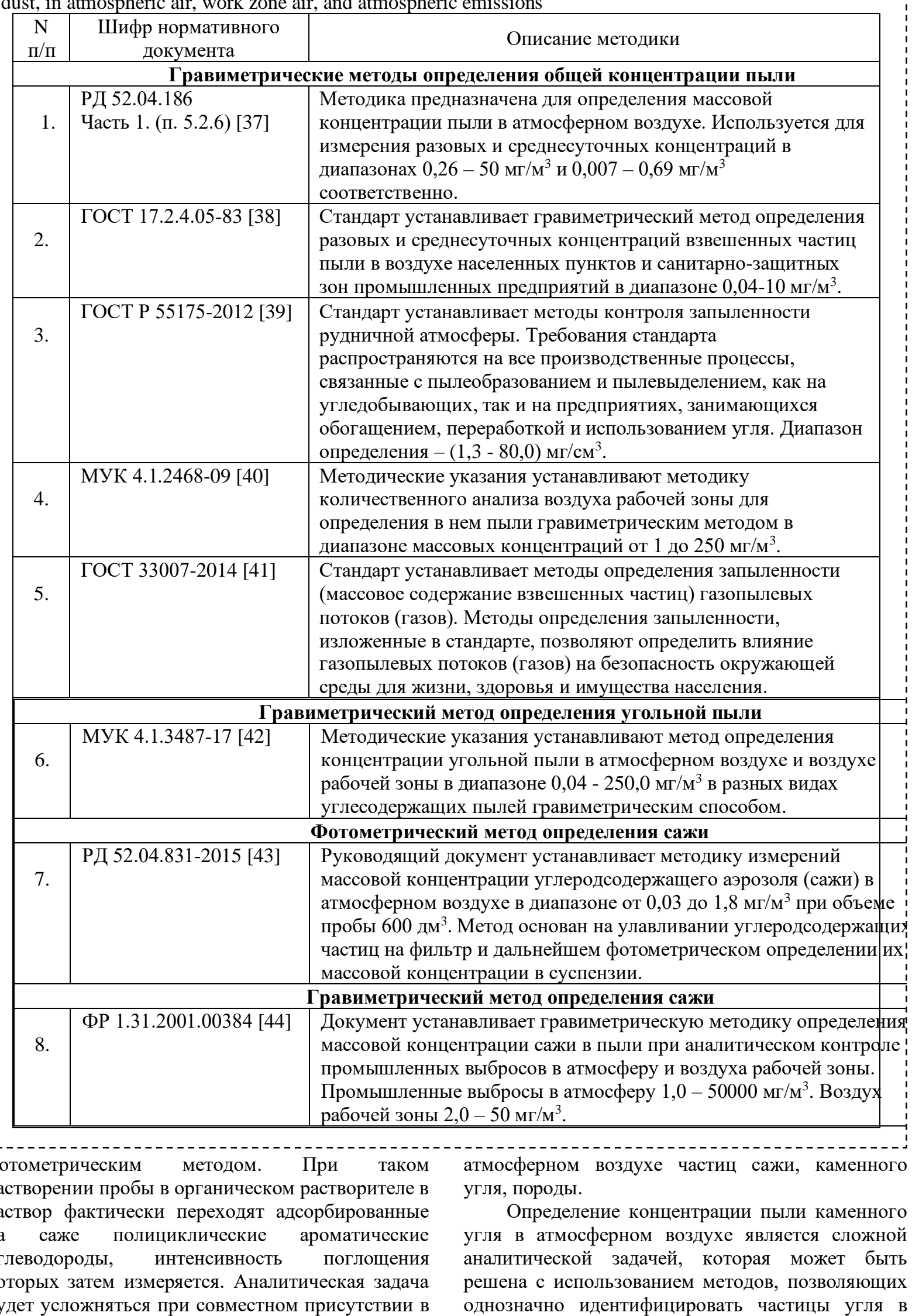


пробе (петрография, сканирующая электронная микроскопия). Однако такие методы сложны для точных количественных определений и доступны только в исследовательских лабораториях.

Таким образом, для получения объективной информации о загрязнении атмосферного воздуха в зоне действия предприятий по добыче и переработке углей необходимо выполнять контроль по целому комплексу показателей, включающих определение угольной пыли, взвешенных частиц с размерами менее 10 мкм (РМ10) и с размерами менее 2,5 мкм (РМ2,5), полициклических ароматических углеводородов, токсичных углефильных элементов.

Исследование выполнено при финансовой поддержке РФФИ и Департамента образования и науки Кемеровской области в рамках научного проекта № 20-45-420020/20.

\section{СПИСОК ЛИТЕРАТУРЫ}

1. John S. French Probable Causes of Adverse Effects of Chronic Coal Dust Exposure on Human and Environmental Health (preliminary analysis), Pegasus Environmental Services - Alaska https://www.thescca.ca/documents/Coal/BriefingChronicCoal.pdf. Дата обращения: 30.04.2020 г.

2. Шпирт М.Я. Микроэлементы горючих ископаемых / М.Я. Шпирт, В.В. Рашевский - М. Кучково поле, 2010. - 384 c.

3. Юдович Я.Э. Ценные элементы-примеси в углях / Я.Э. Юдович, М.П. Кетрис - Екатеринбург: УрО PAH, 2006. - 539 c.

4. Распоряжение Правительства РФ от 08.07.2015 г. N 1316-р «Об утверждении перечня загрязняющих веществ, в отношении которых применяются меры государственного регулирования в области охраны окружающей среды». - Режим доступа: http://base.garant.ru/71126758. Дата обращения 30.04.2020 г.

5. Гигиенические нормативы ГН 2.1.7.2511-09. Ориентировочно допустимые концентрации (ОДК) химических веществ в почве. Утв. постановлением Главного государственного санитарного врача РФ от 18 мая 2009 г. N 32. Режим доступа: https://base.garant.ru/12167919/53f89421bbdaf741eb2d1ecc4ddb4c33. Дата обращения: 30.04.2020 г.

6. Журавлева Н.В. Содержание токсичных элементов во вскрышных и вмещающих породах угольных месторождений Кемеровской области / Н.В. Журавлева, О.В. Иваныкина, 3.Р. Исмагилов, Р.Р. Потокина // Горный информационно-аналитический бюллетень. - 2015. - № 3. - С. 187-197.

7. Журавлева Н.В. Изучение распределения токсичных элементов в золошлаковых отходах предприятий топливно-энергетического комплекса Кемеровской области / Н.В. Журавлева, О.В. Иваныкина, 3.Р. Исмагилов // Химия в интересах устойчивого развития. - 2013. - Т. 21. - С. 479-486.

8. Журавлева Н.В. Изучение распределения макро- и микроэлементов в отходах углеобогащения / Н.В. Журавлева, Р.Р. Потокина, З.Р. Исмагилов, Н.В. Нагайцева // Химия в интересах устойчивого развития. - 2016. - Т. 24. - № 6. - С. 761-767.

9. Авгушкевич И.В. Стандартные методы испытания углей. Классификация углей. / И.В. Авгушкевич, Е.И. Сидорук, Т.М. Броновец - М.: «Реклама мастер», 2018. 576 с. ISBN 978-5-902989-59-2.

10.Laumann S. Variations in concentrations and compositions of polycyclic aromatic hydrocarbons (PAHs) in coals related to the coal rank and origin / S. Laumann, V. Micic, M. A. Kruge, C. Achten, T. Hofmann // Environmental Pollution. - 2011. - Vol. 159. - P. 2690-2697.

11.Achten C. Native polycyclic aromatic hydrocarbons (PAH) in coals - A hardly recognized source of environmental contamination / C. Achten, T. Hofmann // Science of the Total Environment. - 2009. - V. 407. P. $2461-2473$

12.Zhao Z.B. Soluble polycyclic aromatic hydrocarbons in raw coals / Z.B. Zhao, K. Liu, W. Xie, W. P. Pan, J.T. Riley // Journal of Hazardous Materials. - 2000. - Vol. 73. - P. 77-85.

13.Wang R. Abundances of polycyclic aromatic hydrocarbons (PAHs) in 14 Chinese and American coals and their relation to coal rank and weathering / R. Wang, L. Guijian, Z. Jiamei, C. Chen-Lin, L. Jingjing // Energy Fuels. - 2010. - № 24. - P. 6061-6066.

14.Gao B. Distributions of polycyclic aromatic hydrocarbons in coal in China / B. Gao, Q. Feng, L. Zhou, H. Wu, E. Ala // Pol. J. Environ. Stud. - 2019. - V. 28, No. 3. - P. 1665-1674. DOI: 10.15244/pjoes/89899. 
15.Yan C. Polycyclic aromatic hydrocarbons (PAHs) in Chinese coal: occurrence and sorption mechanism / C. Yan, Y. Yang, M. Liu, M. Nie, L. Gu, J. L. Zhou // Environmental Earth Sciences. - 2014. - Issue 2.

16.Журавлева Н.В. Обоснование, разработка и развитие методов оценки влияния добычи и переработки углей Кузнецкого угольного бассейна на экологическое состояние природной среды: дис. ... докт. техн. наук. Кемерово, 2017. 341 с.

17.Журавлева, Н.В. Определение полициклических ароматических углеводородов в углях методом высокоэффективной жидкостной хроматографии / Н. В. Журавлева, Р.Р. Потокина, 3.Р. Исмагилов, Е.Р. Хабибулина // Химия в интересах устойчивого развития. - 2015. - Т. 23. - № 2. - С. 117-123.

18.Журавлева, Н.В. Изучение взаимосвязи строения ископаемых углей и содержания в них полициклических ароматических углеводородов / Н.В. Журавлева, Е.Р. Хабибулина, З.Р. Исмагилов, Р.Р. Потокина, С.А. Созинов // Химия в интересах устойчивого развития. - 2016. - Т. 24. - № 3. - С. 355-361.

19.Журавлева Е.В., Михайлова Е.С., Журавлева Н.В., Исмагилов 3.Р. Полициклические ароматические углеводороды из углей в объектах окружающей среды // Химия в интересах устойчивого развития. - 2020. - Том 28. - № 3. - С. 328-337.

20.Попова С.А., Макаров В.И., Куйбида Л.В. Сезонная изменчивость н-алканов и полиядерных ароматических углеводородов в атмосфере Новосибирска и его пригорода // Оптика атмосферы и океана. - 2008. - T. 21. - № 6. - С. 536-539.

21.Zhuravleva N.V., Khabibulina E.R., Ismagilov Z.R., Efimova O.S., Osokina A.A., Potokina R.R. Chemical and Granulometric Composition of Particles of Solid Atmospheric Aerosol Including Black Carbon in the Snowpack on the Territory of the Industrial Zone of Novokuznetsk City // Химия в интересах устойчивого развития. - 2016. - Т. 24. - № 4. - С. 509-519.

22.Liu D., Lin T., Syed J.H., Cheng Z., Xu Y., Kechang Li K., Zhang G., Li J. Concentration, source identification, and exposure risk assessment of PM2.5-bound parent PAHs and nitro-PAHs in atmosphere from typical Chinese cities // Scientific Reports 7. 2017. https://doi.org/10.1038/s41598-017-10623-4.

23.Mo Z., Wang Z., Mao G., Pan X., Wu L., Xu P., Chen S., Wang A., Zhang Y., Luo J., Ye X., Wang X., Chen Z., Lou X. Characterization and health risk assessment of PM2.5-bound polycyclic aromatic hydrocarbons in 5 urban cities of Zhejiang Province, China // Scientific Report. 2019. V. 9. https://doi.org/10.1038/s41598-01943557-0.

24.Hassanvand M.S. Characterization of PAHs and metals in indoor/outdoor PM10/PM2.5/PM1 in a retirement home and a school dormitory // Science of the Total Environment. 2015. Vol. 527-528. P. 100-110. https://doi.org/10.1016/j.scitotenv.2015.05.001.

25.Джамиль А.К.М. Рахман, Кантор Л.И., Дружинская Е.В., Кантор Е.А. Анализ содержания бенз(а)пирена в различных створах р. Уфы // Башкирский химический журнал. - 2014. - Т. 21. - № 2. - С. $117-124$.

26.Аргучинцев В.К., Макухин В.Л. Моделирование на постилающей поверхности полициклических ароматических углеводородов в регионе Южного Байкала // Оптика атмосферы и океана. $-2000 .-$ Т. 13. № 6-7. - С. 631-632.

27.Маринайте И.И. Полициклические ароматические углеводороды в воде притоков Южного Байкала // Оптика атмосферы и океана. - 2006. - Т. 19. - № 6. - С. 499-503.

28.Журавлева Н.В., Потокина Р.Р., Исмагилов 3.Р., Хабибулина Е.Р. Загрязнение снегового покрова полициклическими ароматическими углеводородами и токсичными элементами на примере г. Новокузнецка // Химия в интересах устойчивого развития. - 2014. - Т. 22. - № 5. - С. 445-454.

29.Zhang, Liu J., Huang F., Wang H., Xu R. Occurrence, risk and influencing factors of polycyclic aromatic hydrocarbons in surface soils from a large-scale coal mine, Huainan, China // Ecotoxicology and Environmental Safety. - 2020. - Vol. 192. https://doi.org/10.1016/j.ecoenv.2020.110269.

30.Sushkova S., Minkina T., Deryabkina I., Rajput V., Antonenko E., Nazarenko O., Yadav B.K., Hakki E., Mohan D. Environmental pollution of soil with PAHs in energy producing plants zone // Science of the Total Environment. - 2019. - Vol. 655. - P. 232-241. DOI: 10.1016/j.scitotenv.2018.11.080.

31.Qi H. X., Chen X. L. , Du Y. E. , Niu X. J., Guo F., Li, W. X. Cancer risk assessment of soils contaminated by polycyclic aromatic hydrocarbons in Shanxi, China // Ecotoxicology and environmental safety. Vol. 182. UNSP 109381. DOI: 10.1016/j.ecoenv.2019.109381. 
32.Белых Л.И., Горшков А.Г., Рябчикова И.А., Серышев В.А. Распределение и биологическая активность полициклических ароматических углеводородов в системе источник-снежный покров-почварастение // Сибирский экологический журнал. - 2004. - № 6. - С. 793-802.

33.Горшков А.Г., Михайлова Т.А., Бережная Н.С., Верещагин А.Л. Хвоя сосны обыкновенной (Pinus sylvestris L.) как биоиндикатор загрязнения атмосферы полициклическими ароматическими углеводородами // Химия в интересах устойчивого развития. - 2008. - Т. 16. - С. 159-166.

34.Air quality guidelines for Europe. WHO Regional Publications, European Series, No. 91. Second edition, 2000. ISBN $\quad 92 \quad 890 \quad 1358 \quad 3 . \quad$ Режим доступа: http://www.euro.who.int/_data/assets/pdf_file/0005/74732/E71922.pdf?ua=1. Дата обращения: 01.05.2020 г.

35.ГН 2.1.6.3492-17. Предельно допустимые концентрации (ПДК) загрязняющих веществ в атмосферном воздухе городских и сельских поселений. Утв. постановлением главного государственного санитарного врача РФ от 22 декабря 2017 года N 165. Режим доступа: http://docs.cntd.ru/document/556185926. Дата обращения: 28.04.2020 г.

36.Журавлева Н.В. Определение гранулометрического состава угольных порошков методом лазерной дифракции / Н.В. Журавлева, Р.Р. Потокина, 3.Р. Исмагилов // ХТТ. - 2016. - № 5. - С. 56-62.

37.РД 52.04.186-89. Руководство по контролю загрязнения атмосферы (Часть І. Разделы 1-5). Введ. 01.07.1991. - М: Госкомгидромет и Министерство здравоохранения СССР. Режим доступа: http://docs.cntd.ru/document/1200036406. Дата обращения: 28.04.2020 г.

38.ГОСТ 17.2.4.05-83. Охрана природы. Атмосфера. Гравиметрический метод определения взвешенных частиц пыли. Введ. 20.12.1983. - М.: Издательство стандартов, 1984. - 4 с. Режим доступа: http://docs.cntd.ru/document/1200012793. Дата обращения: 28.04.2020 г.

39.ГОСТ Р 55175-2012. Атмосфера рудничная. Методы контроля запыленности. Введ. 01.12.2013. М.: Стандартинформ, 2019. - 20 с. Режим доступа: http://docs.cntd.ru/document/1200096585. Дата обращения: 28.04 .2020 г.

40.МУК 4.1.2468-09. Измерение массовых концентраций пыли в воздухе рабочей зоны предприятий горнорудной и нерудной промышленности. Введ. 29.04.2009. - М.: Федеральный центр гигиены и эпидемиологии Роспотребнадзора, 2009. Режим доступа: http://docs.cntd.ru/document/898911988. Дата обращения: 28.04 .2020 г.

41.ГОСТ 33007-2014. Оборудование газоочистное и пылеулавливающее. Методы определения запыленности газовых потоков. Общие технические требования и методы контроля. Введ. 01.12.2015. - М.: Стандартинформ, 2015. - 32 с. Режим доступа: http://docs.cntd.ru/document/1200121305. Дата обращения: 28.04.2020 г.

42.МУК 4.1.3487-17. Измерение концентраций угольной пыли в атмосферном воздухе и в воздухе рабочей зоны гравиметрическим методом. - М.: 2017. - 12 с. Режим доступа: https://www.rospotrebnadzor.ru/upload/iblock/f27/muk-4.1.3487_17-ugolnaya-pyl-_-na-sayt.pdf. Дата обращения: 28.04 .2020 г.

43.РД 52.04.831-2015. Массовая концентрация углеродсодержащего аэрозоля в пробах атмосферного воздуха. Методика измерений фотометрическим методом. Введ. 01.03.2016. - СПб.: Министерство природных ресурсов и экологии Российской Федерации; Росгидромет. 2018. - 28 с. Режим доступа: https://docplan.ru/Data2/1/4293755/4293755338.pdf. Дата обращения: 28.04.2020 г.

44.ФР 1.31.2001.00384. Методика измерения массовой концентрации сажи в промышленных выбросах и в воздухе рабочей зоны. Ярославль: ОАО НИИ «Техуглерод», 2015 - 11 с. Режим доступа: https://standartgost.ru/g/\%D0\%A4\%D0\%A0_1.31.2001.00384. Дата обращения: 28.04.2020 г.

\section{REFERENCES}

1. John S. French Probable Causes of Adverse Effects of Chronic Coal Dust Exposure on Human and Environmental Health (preliminary analysis), Pegasus Environmental Services - Alaska https://www.thescca.ca/documents/Coal/BriefingChronicCoal.pdf. Дата обращения: 30.04 .2020 г.

2. Shpirt M.Ya. Microelements of fossil fuel / M.Ya. Shpirt, V.V. Rashevsky - M.: Kuchkovo field, 2010. - 
$384 \mathrm{p}$.

3. Yudovich Ya.E. Valuable elements-impurities in coal / Ya.E. Yudovich, M.P. Ketris-Yekaterinburg: Uro RAS, 2006. -539 p.

4. Order of the Russian Federation Government of 08.07.2015 N 1316-R "On approval of the list of pollutants for which state regulation measures in the field of environmental protection are applied". - Access mode: http://base.garant.ru/71126758. Date of access: 30.04.2020.

5. Hygiene standards GN 2.1.7.2511-09. Approximate permissible concentrations of chemicals in the soil. Approved by the resolution of the Chief state sanitary doctor of the Russian Federation of May 18, 2009 N 32. Access mode: https://base.garant.ru/12167919/53f89421bbdaf741eb2d1ecc4ddb4c33. Date of access: 30.04.2020.

6. Zhuravleva N.V. Content of toxic elements in overburden and host rocks of coal deposits of the Kemerovo region / N.V. Zhuravleva, O.V. Ivanykina, Z. R. Ismagilov, R. R. Potokina // Mining information and analytical Bulletin. - 2015. - № 3. - P. 187-197.

7. Zhuravleva N.V., Ivanykina O.V., Ismagilov Z.R. Studying the distribution of toxic elements in ash-andslag wastes from the enterprises of the fuel-and-energy complex of the Kemerovo region // Chemistry for sustainable development. - 2013. - Vol. 21. - P. 479-486.

8. Zhuravleva N.V., Potokina R.R., Ismagilov Z.R., Nagaytseva N.V. Study of the distribution of macro and microelements in coal preparation wastes of the Kuznetsk coal basin // Chemistry for sustainable development. 2016. - Vol. 24. - No. 6. - P. 761-767.

9. Avgustevich I.V. Standard methods of coals analysis. Classification of coals. / I. V. Avgushkevich, E.I. Sidoruk, T.M. Bronovets-M.: «Advertising master», 2018. 576 p. ISBN 978-5-902989-59-2.

10.Laumann S., Micic V., Kruge M.A., Achten C., Hofmann T. Variations in concentrations and compositions of polycyclic aromatic hydrocarbons (PAHs) in coals related to the coal rank and origin // Environmental Pollution. - 2011. - Vol. 159. - P. 2690-2697.

11.Achten C., Hofmann T. Native polycyclic aromatic hydrocarbons (PAH) in coals - A hardly recognized source of environmental contamination // Science of the Total Environment. - 2009. - V. 407. - P. 2461 - 2473.

12.Zhao Z.B., Liu K., Xie W., Pan W.P., Riley J.T. Soluble polycyclic aromatic hydrocarbons in raw coals // Journal of Hazardous Materials. - 2000. - Vol. 73. - P. 77-85.

13.Wang R., Guijian L., Jiamei Z., Chen-Lin C., Jingjing L. Abundances of polycyclic aromatic hydrocarbons (PAHs) in 14 Chinese and American coals and their relation to coal rank and weathering // Energy Fuels. - 2010. - № 24. - P. 6061-6066.

14.Gao B., Feng Q., Zhou L., Wu H., Ala E. Distributions of polycyclic aromatic hydrocarbons in coal in China // Pol. J. Environ. Stud. - 2019. - V. 28, - No. 3. - P. 1665-1674. DOI: 10.15244/pjoes/89899.

15.Yan C., Yang Y., Liu M., Nie M., Gu L., Zhou J. L. Polycyclic aromatic hydrocarbons (PAHs) in Chinese coal: occurrence and sorption mechanism // Environmental Earth Sciences. - 2014. - Issue 2.

16.Zhuravleva N.V. Substantiation, development and amplification of the methods for assessing the impact of coal mining and processing of the Kuznetsk coal basin on the ecological state of the environment: dis. ... doctor. tech. sciences. Kemerovo, 2017. 341 p.

17.Zhuravleva N.V., Potokina R.R., Ismagilov Z.R., Khabibulina E.R. Determination of polycyclic aromatic hydrocarbons in coal by high-performance liquid chromatography // Chemistry for Sustainable Development. 2015. - Vol. 23. - № 2. - P. 117-123.

18.Zhuravleva N.V., Khabibulina E.R., Ismagilov Z.R., Potokina R.R., Sozinov S.A. Studies of the interconnection of the structure of fossil coal and the concentrations of polycyclic aromatic hydrocarbons in it / N.V. Zhuravleva, E.R. Khabibulina, Z.R. Ismagilov, R.R. Potokina, S.A. Sozinov// Chemistry for Sustainable Development. - 2016. - Vol. 24. - № 3. - P. 355-361.

19.Zhuravleva E.V., Mikhailova E.S., Zhuravleva N.V., Ismagilov Z.R. Polycyclic aromatic hydrocarbons from coal in the environmental objects // Chemistry for sustainable development. -2020 . - Vol. 28. - № 3. - P. 328-337.

20.Popova S.A., Makarov V.I., Kuibida L.V. Seasonal variability of n-alkanes and poly-nuclear aromatic hydrocarbons in the atmosphere of Novosibirsk and its suburbs // Atmospheric and Oceanic Optics. - 2008. - Vol. 21. - № 6. - P. 536-539.

21.Zhuravleva N.V., Khabibulina E.R., Ismagilov Z.R., Efimova O.S., Osokina A.A., Potokina R.R. Chemical and Granulometric Composition of Particles of Solid Atmospheric Aerosol Including Black Carbon in 
the Snowpack on the Territory of the Industrial Zone of Novokuznetsk City // Himiya v interesah ustojchivogo razvitiya. - 2016. - T. 24. - № 4. - C. 509-519.

22.Liu D., Lin T., Syed J.H., Cheng Z., Xu Y., Kechang Li K., Zhang G., Li J. Concentration, source identification, and exposure risk assessment of PM2.5-bound parent PAHs and nitro-PAHs in atmosphere from typical Chinese cities // Scientific Reports 7. 2017. https://doi.org/10.1038/s41598-017-10623-4.

23.Mo Z., Wang Z., Mao G., Pan X., Wu L., Xu P., Chen S., Wang A., Zhang Y., Luo J., Ye X., Wang X., Chen Z., Lou X. Characterization and health risk assessment of PM2.5-bound polycyclic aromatic hydrocarbons in 5 urban cities of Zhejiang Province, China // Scientific Report. 2019. V. 9. https://doi.org/10.1038/s41598-01943557-0.

24.Hassanvand M. S. Characterization of PAHs and metals in indoor/outdoor PM10/PM2.5/PM1 in a retirement home and a school dormitory // Science of the Total Environment. 2015. Vol. 527-528. P. 100-110. https://doi.org/10.1016/j.scitotenv.2015.05.001.

25.Jamil A.K.M. Rakhman, Kantor L.I., Druzhinskaya E.V., Kantor E.A. Analysis of the con-tent of benz(a)pyrene in various sections of the river Ufa // Bashkir Chemical Journal. - 2014. - Vol. 21. - № .2. - P. $117-124$.

26.Arguchintsev V.K., Makukhin V.L. Modeling on the underlying surface of polycyclic aromatic hydrocarbons in the South Baikal region // Atmospheric and Oceanic Optics. - 2000. - Vol. 13. - №. 6-7. - P. 631-632.

27.Marinaite I. Polycyclic aromatic hydrocarbons in water inflows Southern lake // Atmospheric and Oceanic Optics. - 2006. - Vol. 19. - № 6. - P. 499-503.

28.Zhuravleva N.V., Potokina R.R., Ismagilov Z.R., Khabibulina E.R. Pollution of Snow Cover with Polycyclic Aromatic Hydrocarbons and Toxic Elements for Novokuznetsk as Example // Chemistry for Sustainable Development. - 2014. - Vol. 22. - № 5. - P. 445-454.

29.Zhang, Liu J., Huang F., Wang H., Xu R. Occurrence, risk and influencing factors of polycyclic aromatic hydrocarbons in surface soils from a large-scale coal mine, Huainan, China // Ecotoxicology and Environmental Safety. 2020. Vol. 192. https://doi.org/10.1016/j.ecoenv.2020.110269.

30.Sushkova S., Minkina T., Deryabkina I., Rajput V., Antonenko E., Nazarenko O., Yadav B.K., Hakki E., Mohan D. Environmental pollution of soil with PAHs in energy producing plants zone // Science of the Total Environment. - 2019. - Vol. 655. - P. 232-241. DOI: 10.1016/j.scitotenv.2018.11.080.

31.Qi H. X., Chen X. L., Du Y. E. , Niu X. J., Guo F., Li, W. X. Cancer risk assessment of soils contaminated by polycyclic aromatic hydrocarbons in Shanxi, China // Ecotoxicology and environmental safety. Vol. 182. UNSP 109381. DOI: 10.1016/j.ecoenv.2019.109381.

32.Belykh L.I., Gorshkov A.G., Ryabchikova I.A., Seryshev V.A. Distribution and biological activity of polycyclic aromatic hydrocarbons in the source-snow cover-soil-plant system // Siberian ecological journal. 2004. - № 6. - P. 793-802.

33.Gorshkov A.G., Marinaite I.I., Baram G.I., Sokov I.A. Application of high-performance liquid chromatography on short columns of small diameter for determining priority polycyclic aromatic hydrocarbons in environmental objects // Journal of analytical chemistry. - 2003. - Vol. 58. - № 8. - P. 861-868.

34.Air quality guidelines for Europe. WHO Regional Publications, European Series, No. 91. Second edition, 2000. ISBN $92 \quad 890 \quad 1358 \quad 3 . \quad$ Rezhim dostupa: http://www.euro.who.int/_data/assets/pdf_file/0005/74732/E71922.pdf?ua=1. Data obrashcheniya: 01.05.2020.

35.GN 2.1.6.3492-17. Maximum permissible concentrations (MPC) of pollutants in the atmospheric air of urban and rural settlements. Approved by the resolution of the chief state sanitary doctor of the Russian Federation of December 22, 2017 N 165. Access mode: http://docs.cntd.ru/document/556185926. Date of access: 28.04.2020

36.Zhuravleva N.V., Potokina R.R., Ismagilov Z.R. Determination of the granulometric composition of coal powders by laser diffraction // Solid fuel chemistry. - 2016. - № 5. - P. 56-62.

37.RD 52.04.186-89. Air pollution control manual (Part I. Sections 1-5). No. 01.07.1991. - M: Goskomgidromet and the Ministry of health of the USSR. Access mode: http://docs.cntd.ru/document/1200036406. Date of access: 28.04.2020.

38.GOST 17.2.4.05-83. Nature protection. Atmosphere. Gravimetric method for determining suspended dust particles. No. 20.12.1983. - Moscow: publishing house of standards, 1984. - 4 p. Access mode: http://docs.cntd.ru/document/1200012793. Date of access: 28.04.2020. 
39.GOST R 55175-2012. The mining atmosphere. Methods of dust control. No. 01.12.2013. - Moscow: standardinform, 2019. - 20 p. Access mode: http://docs.cntd.ru/document/1200096585. Date of access: 28.04.2020.

40.MUC 4.1.2468-09. Measurement of mass concentrations of dust in the air of the working area of mining and non-metallic industry enterprises. No. 29.04.2009. - Moscow: Federal center for hygiene and epidemiology of Rospotrebnadzor, 2009. Access mode: http://docs.cntd.ru/document/898911988. Date of access: 28.04.2020.

41.GOST 33007-2014. Gas-cleaning and dust-collecting equipment. Methods for determining the dustiness of gas flows. General technical requirements and control methods. No. 01.12.2015. - Moscow: standardinform, 2015. - 32 p. Access mode: http://docs.cntd.ru/document/1200121305. Date of access: 28.04.2020.

42.MUC 4.1.3487-17. Measurement of coal dust concentrations in atmospheric air and in the air of the working area by gravimetric method. - Moscow: 2017. - 12 p. Access mode: https://www.rospotrebnadzor.ru/upload/iblock/f27/muk-4.1.3487_17-ugolnaya-pyl-_-na-sayt.pdf. Date of access: 28.04.2020.

43.RD 52.04.831-2015. Mass concentration of carbon-containing aerosol in atmospheric air samples. Methodology of measurement by the photometric method. No. 01.03.2016. - Saint Petersburg: Ministry of natural resources and ecology of the Russian Federation; Roshydromet. 2018. - 28 p. Access mode: https://docplan.ru/Data2/1/4293755/4293755338.pdf. Date of access: 28.04.2020.

44.FR 1.31.2001.00384. Method for measuring the mass concentration of soot in industrial emissions and in the air of the working area. Yaroslavl: JSC research Institute "techuglerod", 2015. - 11 p. Access mode:

https://standartgost.ru/g/\%D0\%A4\%D0\%A0_1.31.2001.00384. Date of access: 28.04.2020. 